\title{
FORMAÇÃO CONTINUADA PARA DOCENTES dO ENSINO SUPERIOR DA UNIVERSIDADE DO VALE DO ITAJAÍ: O OLHAR DE FORMADORAS DO GEPES/UNIVALI
}

CONTINUED FORMATION TO HIGHER EDUCATION TEACHER OF

UNIVERSITY OF VALE DO ITAJAI: THE LOOK OF TRAINERS OF GEPES/UNIVALI

FORMACION CONTINUA PARA DOCENTES DE EDUCACIÓN

SUPERIOR DE LA UNIVERSIDAD DO VALE DO ITAJAÍ:

BAJO LA VISION DE LAS FORMADORAS GEPES/UNIVALI

Kátia Naomi Kuroshima ${ }^{1}$ Yára Christina Cesário Pereira ${ }^{2}$ Marlete dos Santos Dacoreggio ${ }^{3}$ Claudia Kuinta Dias Hohmann ${ }^{4}$ Sueli Petry da Luz

\section{RESUMO}

Este relato de experiências apresenta o olhar de cinco formadoras do Grupo de Estudos e Pesquisas em Educação Superior - GEPES/UNIVALI, ao Programa de Formação Continuada para Docentes do Ensino Superior dessa instituição, doravante FC-UNIVALI. O objetivo geral visa destacar experiências relevantes de docentes profissionais formadoras com seus pares no referido Programa. Os objetivos específicos são: refletir sobre o seu significado; identificar os aspectos positivos; descrever conflitos, tensões e dificuldades e, apresentar aspectos indispensáveis das formadoras no ato da formação. As razões norteadoras para elaboração do artigo são: ser formadora da FC-UNIVALI é desafiador, principalmente, por ser um trabalho com seus pares; a necessidade de se socializar experiências, sobre a atuação de formadoras, dada as poucas publicações. Metodologicamente, o programa sofreu adaptações nos formatos de operacionalização desde a sua implantação em 2000, cuja participação docente era voluntária. Oficinas, palestras, conferências, mesas-redondas, relatos de experiência, videoconferências, atividades EAD, entre outros, contemplam temáticas institucionais e específicas, durante os meses de fevereiro e julho, nos três turnos, em todos os campi. A partir dos conteúdos desenvolvidos, neste artigo, tem-se, como consideração final, que ser formadora é exercitar e transitar no campo das atitudes, habilidades e competências da docência, do ser professor reflexivo e pesquisador, dialogando e superando os desafios e enfrentamentos pedagógicos, em prol do desenvolvimento humano, social e da qualidade do ensino superior, estabelecido numa política de ensino institucional. Espera-se que este artigo contribua com outras reflexões, estudos e pesquisas sobre o papel do formador nesse tipo de formação.

PALAVRAS-CHAVE: Formação continuada no ensino superior. Papel do formador. Formação para os pares.

\footnotetext{
${ }^{1}$ Doutora em Química pela UFSC e mestre em Geoquímica Ambiental pela UFF. Professora da Universidade do Vale do Itajaí. E-mail: kuroshima@univali.br

${ }^{2}$ Pós-doutora em Educação Ambiental pela Universidade Federal do Rio Grande; doutora e mestre em Educação pela UFSC. Professora titular da Universidade do Vale do Itajaí. E-mail: yara@ univali.br

${ }^{3}$ Mestre e doutora em Educação pela UFSC. Professora titular da Universidade do Vale do Itajaí. E-mail: marleted@univali.br

${ }^{4}$ Pós-Doutora em Educação pelo FURG; doutora em Educação pela Universidade de León (Espanha). Pesquisadora da UNIVALI. E-mail: claudiah@univali.br

${ }^{5}$ Doutora em Educação pela Faculdade UNICAMP; mestre em Educação pela UFRGS. Atuou na área da administração universitária, como Pró-Reitora de Graduação na Universidade do Vale do Itajaí. E-mail: petryluz@univali.br
}

Submetido em: 01/08/2016 - Aceito em: 04/09/2016.

\begin{tabular}{l|l|l|l|l|l|l} 
(C) Rev. Inter. Educ. Sup. & Campinas, SP & v.2 & n.2 & p.366-381 & maio/ago. 2016 & ISSN 2446-9424 \\
\hline
\end{tabular}




\section{ABSTRACT}

This experience report presents the five trainer look belonging Study and Research Group in Higher Education GEPES/UNIVALI, for Continued Formation Program to Higher Education by University of Vale do Itajaí - CFUNIVALI. The main objective aims to highlight relevant experiences of trainer teachers with their peers in that program. Specific objectives are: reflect to its meaning, identify the positive aspects, describe conflicts, tensions and difficulties and provide essential aspects in the training. The main reasons for the preparation of the article are: be a trainer in CF-UNIVALI is challenging, mainly because it is a work with their peers: the need to socialize experience, about the training performance, given the few publications. Its methodology showed changes in its operational formats since its implementation in 2000, whose teaching participation was voluntary. Workshops, lectures, conferences, round table, experience reports, video conference, distance education activities, and others, include institutional and specific themes, during the months of February and July, in three shifts, in all campus. Based on content developed in this article, we have as final consideration, that, to be a trainer is to exercise and transit in the field of attitudes, skills and competences of teaching, be reflective and researcher teacher, talking and overcoming the challenges and pedagogical confrontation, in support of human and social development and quality of higher education, established at institutional education policy. It is hope that this article contributes other reflections, studies and research on the role of the trainer in this type of training.

KEYWORDS: Continued formation to higher education. Trainer's role. Training to their peers.

\section{RESUMEN}

Este relato de experiencias expone la visión de cinco formadoras del Grupo de Estudios y Investigación en Educación Superior - GEPES/UNIVALI, al Programa de Educación Continuada para Docente de Educación Superior de esa institución (FC UNIVALI). El objetivo general pretende resaltar experiencias importantes de docentes profesionales, formadoras de sus colegas en el citado Programa, mientras los específicos, son reflexionar sobre su significado; identificar los aspectos positivos; describir los conflictos, tensiones y dificultades e, mostrar aspectos indispensables en el acto de la formación. Las principales razones para o presente artículo fueron: ser formadora de la FC-UNIVALI es desafiador, principalmente, por ser un trabajo con sus colegas; la necesidad de socializar experiencias, sobre la acción de las formadoras, debido a las pocas publicaciones. A la metodología, hubo ajustes en formatos operativos desde su implementación en 2000, cuya participación fue voluntaria enseñanza. Talleres, conferencias, informes de experiencias, videoconferencia, actividades de enseñanza a distancia, incluyen temas institucionales y específicos durante los meses de febrero y julio, en tres turnos, en todos los campus. Tiene como consideración final, que ser formadora es practicar y transitar en el área de las actitudes, las habilidades y competencias de la enseñanza; de ser profesor reflexivo e investigador, dialogando y superando los desafíos y conflictos pedagógicos, en favor del desarrollo humano, social y de la calidad de la educación superior, establecido en la política educativa institucional. Se espera que este artículo contribuya con otras reflexiones, estudios y investigaciones sobre el papel del formador en ese tipo de educación.

PALABRAS CLAVE: Formación continua de educación superior. Papel de las formadoras. Formación para sus colegas.

\section{INTRODUÇÃO}

Este relato de experiências apresenta o olhar de cinco formadoras do GEPES/UNIVALI (Grupo de Estudos e Pesquisas em Educação Superior), ao Programa de Formação Continuada para Docentes do Ensino Superior dessa instituição, doravante FCUNIVALI. O Programa nasceu em 2000 e, desde seu início, possui um caráter científico, com larga produção de saberes e fazeres do que acontece semestralmente. Ao final de cada etapa do processo, é realizada uma avaliação, cujos resultados são utilizados para o planejamento da próxima FC-UNIVALI. Fato elogiável é que, além dos docentes, reitor, vice-reitores, diretores, coordenadores tem envolvimento e participação direta. 
As docentes profissionais, que aqui escrevem, são ou foram formadoras no FCUNIVALI. Constitui a fala, a opinião, o pensamento e a experiência de membros do GEPES/UNIVALI. É a expressão de seus saberes e fazeres profissionais oriundos de estudo, sistematização, construção e produção de conhecimento.

O objetivo geral do presente artigo tem em vista destacar experiências relevantes de docentes profissionais formadoras com seus pares, na FC-UNIVALI. Os específicos, na qualidade de formadora, são: refletir sobre o seu significado; identificar os aspectos positivos; descrever conflitos, tensões e dificuldades e, apresentar aspectos indispensáveis no ato da formação.

As justificativas do presente artigo registram que ser formadora da FC-UNIVALI é desafiador, principalmente, por ser um trabalho com seus pares. Normalmente, é uma surpresa de ambas as partes: o desvelamento dos conhecimentos de quem forma e o conhecimento dos que estão sendo formados. É interessante e revelador para ambas as partes. Além disso, a razão maior que motivou o grupo para a apresentação deste artigo constitui a necessidade de se socializar experiências, sobre a atuação de formadoras, dada as poucas publicações.

A estruturação do artigo está composta em quatro seções. A primeira contextualiza a instituição, isto é, a Universidade do Vale do Itajaí, seguido de um situar sobre o Programa de Formação Continuada para Docentes do Ensino Superior da UNIVALI, na segunda seção. A terceira seção explicita sobre o Grupo de Estudos e Pesquisas de Educação SuperiorGEPES/UNIVALI, integrante do grupo do GEPES/GIEPES/UNICAMP-Faculdade de Educação, da Universidade Estadual de Campinas. E, na quarta seção é relatada a experiência das formadoras, agrupadas em quatro subitens, consoante aos objetivos específicos deste artigo.

Espera-se que este artigo contribua e forneça subsídios para outros estudos, reflexões e pesquisas sobre formadores em Programa de Formação Continuada para Docentes do Ensino Superior.

\section{CONTEXTUALIZAÇÃ̃O}

A instalação da Universidade do Vale do Itajaí - doravante UNIVALI - ocorreu em 21 de março de 1989, mas como Instituição de Ensino Superior, sua história remonta a 1964.

Com base nos documentos estatutários e regimentais, a Universidade do Vale do Itajaí é uma instituição de ensino superior municipal comunitária multicampi, não-estatal reconhecida e mantida pela Fundação Universidade do Vale do Itajaí. Como Fundação UNIVALI se caracteriza como pessoa jurídica de direito privado, de finalidade filantrópica e sem fins lucrativos, de natureza beneficente de assistência social, com sede e foro no 
Município e Comarca de Itajaí, Estado de Santa Catarina. Sua missão é "produzir e socializar o conhecimento, pelo ensino, pesquisa e extensão, estabelecendo parcerias solidárias com a comunidade, em busca de soluções coletivas para problemas locais e globais, visando à formação de um cidadão crítico e ético". Tem como visão institucional: "Ser reconhecida como Universidade de excelência na atividade do ensino, no desenvolvimento e divulgação de pesquisas e na gestão criativa e empreendedora de projetos sociais". A UNIVALI alicerça suas bases em valores referenciais de atuação na Instituição: "respeito ao pluralismo de ideias; compromisso social com o desenvolvimento regional e global; produção e uso da tecnologia a serviço da humanidade; ética no relacionamento e formação e profissionalização de vanguarda" (UNIVALI, 2014a e 2014b).

As informações e dados apresentados, nesta seção, tem por base o Plano de Desenvolvimento Institucional 2012-2016 (UNIVALI, 2012), dados disponíveis no site da instituição (UNIVALI, 2016a), bom como de setores acadêmicos e de recursos humanos da instituição.

Como instituição multicampi tem a sede e foro no município de Itajaí e conta com campi distribuídos ao longo de sete municípios do litoral centro-norte catarinense: Balneário Camboriú, Balneário de Piçarras, Biguaçu, Tijucas, São José, Florianópolis e Penha.

A Instituição, em 2016, oferece 84 cursos de graduação nas modalidades bacharelado, licenciatura e tecnólogo, presencial e à distância, abrangendo todas as áreas de conhecimento e agrupadas em seis Centros de Educação: Ciências Sociais e Jurídicas; Ciências Humanas; Ciências Sociais Aplicadas - Comunicação, Turismo e Lazer; Ciências Sociais Aplicadas Gestão; Ciências da Saúde e Ciências Tecnológicas, da Terra e do Mar. Na pós-graduação oferta 44 cursos de pós-graduação lato-sensu e 16 cursos de pós-graduação stricto-sensu, sendo 10 cursos de Mestrado e seis de Doutorado, todos recomendados pela Coordenação de Aperfeiçoamento de Pessoal de Nível Superior (CAPES), do Ministério da Educação (MEC). Conta ainda com uma Escola de Idiomas - NELLE, três Colégios de Aplicação da UNIVALI (educação infantil, ensino fundamental e médio), atuando nos municípios de Itajaí, Balneário Camboriú e Tijucas. Contempla em torno de 25 mil alunos nesses diferentes cursos, modalidade e níveis de ensino.

A UNIVALI apresenta uma infraestrutura com $175 \mathrm{mil} \mathrm{m}^{2}$ de área construída, sendo 588 salas de aulas, 294 laboratórios, 11 bibliotecas, 17 auditórios, um teatro, um Centro de Vivência, dois ginásios, duas quadras de esportes e uma piscina semiolímpica. Seu corpo docente gira em torno de 1,2 mil professores (dos quais, em torno de 78\% possuem título de mestre ou doutor) e em torno de 1,3 mil colaboradores administrativos, sendo $36 \%$ com curso superior completo. Disponibiliza aos alunos oportunidades de intercâmbio, mantendo cerca de 90 acordos de cooperação firmados com países envolvendo todos os continentes.

O Sistema Integrado de Bibliotecas da UNIVALI (Sibiun) é composto por onze bibliotecas, distribuídas ao longo dos seus campi, viabilizando uma maior cooperação entre as bibliotecas; contam com mais de 145mil títulos de livros (com aproximadamente 320,5 mil

\begin{tabular}{l|l|l|l|l|l|l} 
(C) Rev. Inter. Educ. Sup. & Campinas, SP & v.2 & n.2 & p.366-381 & maio/ago. 2016 & ISSN 2446-9424
\end{tabular}


exemplares); mais de 3,8 mil periódicos (128,8 mil exemplares) e outros tipos de materiais, como Literatura Cinzenta e Multimeios. Além disso, possui acesso ao Portal de Periódicos da CAPES/MEC, no qual estão inseridas importantes bases de dados: Web of Science, Scopus, Springer, Wiley e Elsevier, entre outros.

A Instituição mantém como programas e projetos de apoio à extensão e cultura: Programa de Bolsas de Extensão - ProBE; Programa de Assistência Social; Projetos do Artigo 170; Programa Bolsas Extensão; Projetos de Arte e Cultura; Eventos; Prestação de Serviços, Núcleo de Inovação Tecnológica (UNIINOVA), Museu Oceanográfico do Vale do Itajaí (campus Piçarras); Eco Museu UNIVALI (Porto Belo).

Na pesquisa, a UNIVALI também mostra sua atuação ampla e divergente com 114 grupos de pesquisa, dentre os cadastrados no CNPq e os institucionais. Os programas de incentivo à pesquisa da instituição são os seguintes: Programa Institucional de Bolsas de Iniciação Científica - PIBIC-Ensino Médio/CNPq; Programa Institucional de Bolsas de Iniciação Científica - PIBIC-Ensino de graduação/CNPq; Programa de Bolsas de Iniciação Científica - ProBIC; Programa Institucional de Bolsas de Iniciação em Desenvolvimento Tecnológico e Inovação - PIBITI - CNPq; Programa de Bolsas de Pesquisa do Artigo 170 e Artigo 171; Programa Integrado de Pós-Graduação e Graduação (PIPG); Fundo de Apoio à Manutenção e ao Desenvolvimento da Educação Superior no Estado de Santa Catarina FUMDES; Prêmio Mérito Universitário Catarinense - PMUC.

Dos documentos referenciados, nesta seção, há que se destacar que, além da Universidade, a Fundação UNIVALl mantém: o Hospital Universitário Pequeno Anjo; o sistema educativo de rádio e TV UNIVALI; o Laboratório de Produção e Análise de Medicamentos (LAPAM).

A UNIVALI possui vários programas de ensino, pesquisa e extensão, mas o selecionado diz respeito à área de ensino, com referência à Formação Continuada para Docentes.

\section{SITUANDO O PROGRAMA DE FORMAÇÃO CONTINUADA PARA DOCENTES NA UNIVALI}

O Programa de Formação Continuada para Docentes na UNIVALI foi implantado em 2000, mas como capacitação de recursos humanos para docentes do ensino superior e funcionários técnico-administrativos existiu desde que era uma instituição de ensino superior e se chamava FEPEVI - Fundação de Ensino do Pólo Geoeducacional do Vale do Itajaí.

Desde a sua implantação, a estruturação do programa vem incorporando novos formatos, e a partir de 2002 é previsto em calendário acadêmico. Atualmente, é oferecido nos meses de fevereiro e julho, nos períodos matutino, vespertino e noturno, durante duas a três semanas, com programações previstas em todos os campi, ampliando a possibilidade de troca 
de experiências entre os docentes, além de atender às necessidades e especificidades de cada curso, centro ou campus (FERRI, 2009). Oficinas, palestras, conferências, mesas-redondas, relatos de experiência, videoconferências, atividade EAD contemplam temáticas institucionais e específicas. A primeira temática é de responsabilidade da Vice-Reitoria de Graduação em termos de organização, objetivos, formadores e materiais e, geralmente, atendem a objetivos estratégicos ou questões que emergem dos programas de avaliação institucional e projetos pedagógicos dos cursos de graduação. Enquanto a segunda temática, as específicas, ficam sob a responsabilidade de cada curso/centro ou campus, atendendo demandas e interesses específicos.

Até 2006, a participação dos docentes nestas atividades foi voluntária e a partir desse ano, tornou-se obrigatório, sem, no entanto, alterar a participação docente, que sempre oscilou em torno de 75,5\% dos docentes da instituição (FERRI, 2009). O FC-UNIVALI atua, ainda, com subprogramas de tutoria aos docentes ingressantes, formação de coordenadores de curso e formação de formadores, os professores de diversas áreas de conhecimento com afinidade ou desejo de aprofundar os conhecimentos pedagógicos.

Luz (2007) cita diferentes autores que apresentam desafios que levaram os gestores acadêmicos a dar uma atenção especial à implantação do FC-UNIVALI. O principal desafio foi a deficiência didático-pedagógica do docente do ensino superior, apesar de demonstração de elevado conhecimento técnico-científico. Estas deficiências foram observadas cotidianamente e confirmadas pelas queixas dos alunos e, constatadas anualmente por pesquisa de avaliação institucional. A falta de qualificação do professor universitário para o ensino e as deficiências pedagógicas, são também destacadas em Balzan (1997) Veiga (2000), Pachane (2003a e 2003b) e muitos outros. Estas deficiências são mais sentidas pelos profissionais com bacharelado que assumem a docência universitária como outra opção de trabalho (VEIGA, 2000).

Assim, o Programa de Formação Continuada para Docentes na UNIVALI foi criado para se constituir um espaço sistemático de construção do processo de ensino-aprendizagem, da identidade profissional do docente profissional investigativo, de integração entre profissionais "entre e inter" cursos, de discussão das questões relevantes de educação superior e prática pedagógica da sala de aula (UNIVALI, 2001; UNIVALI, 2002; UNIVALI, 2016b; LUZ, 2007).

Ele ocorre por meio da reflexão no movimento de ação-reflexão-ação, possibilitando ao docente: focalizar seu trabalho na melhoria contínua do processo de ensino-aprendizagem; na forma de saber lidar com a complexidade do mundo, "aprendendo com ele e com a multiplicidade de saberes e fazeres que envolvem a docência" e na forma de incentivar a busca por outros saberes (UNIVALI, 2001; UNIVALI, 2002 e UNIVALI, 2016b; LUZ, 2007). Os documentos institucionais reforçam a ideia de que a FC-UNIVALI constitui um investimento institucional visando a qualificação dos docentes, educação superior e o processo de ensino-aprendizagem (UNIVALI, 2016a). 
Os fundamentos básicos e iniciais desse Programa tiveram origem em Nóvoa (1995) acompanhado de outros teóricos como Schön, Zeichner, Sacristán e Pérez-Gómez, mencionados em UNIVALI (2001 e 2002b).

O Programa trabalha com a ideia da formação do docente como desenvolvimento profissional e está fundamentado em grandes eixos temáticos: Saberes da Docência; Política Institucional; Cultura e Formação Geral. Desde que foi implantado, existe uma produção interna sistematizada publicada na série denominada Cadernos de Ensino.

Este Programa e outros vinculados ao ensino são um dos focos de aprofundamento do GEPES-UNIVALI.

\section{APRESENTANDO O GEPES/UNIVALI - GRUPO DE ESTUDOS E PESQUISAS EM EDUCAÇÃO SUPERIOR DA UNIVERSIDADE DO VALE DO ITAJAÍ}

O Grupo de Estudo e Pesquisas em Educação Superior da Universidade do Vale do Itajaí - GEPES/UNIVALI constitui um grupo regional, em formato de rede de ensino, pesquisa, extensão, vinculado ao Grupo de Estudos e Pesquisas em Educação Superior da Universidade Estadual de Campinas - GEPES/UNICAMP e Grupo Internacional de Estudos e Pesquisas sobre Educação Superior - GIEPES/UNICAMP, da Faculdade de Educação da Universidade Estadual de Campinas, doravante abreviado por GEPES/GIEPES/UNICAMP, sob a coordenação da Prof. ${ }^{a}$ Dra. Elisabete Monteiro de Aguiar Pereira.

As linhas de pesquisa do GEPES/UNIVALI articulam-se e se correlacionam com as executadas pelo GEPES/GIEPES/UNICAMP possuindo, também, identidades e especificidades próprias vinculadas ao contexto da educação superior catarinense. $\mathrm{O}$ GEPES/UNIVALI atua, basicamente, em três grandes linhas: educação superior, educação geral e formação de docentes para a educação superior.

Do grupo de docentes, o GEPES/UNIVALI possui cinco doutoras e duas mestres, em fase de doutoramento. Os membros integrantes dedicam-se, basicamente, à estudos referentes: à universidade e educação geral/especializada; ao programa de formação continuada de docentes do ensino superior; à inovação educacional; à inovação curricular e de ensino; à afetividade na prática docente do ensino superior e interdisciplinaridade.

No FC-UNIVALI existe um campo de reflexão e análise para muitos estudos e pesquisas. E, neste sentido, o foco deste artigo centralizou o trabalho de cinco formadoras sobre o referido programa. 


\section{RELATO DE EXPERIÊNCIAS DAS FORMADORAS}

\section{Considerações Iniciais}

Cumpre registrar, antecipadamente, que a equipe de formadores recebe capacitação sobre a temática desde o início do FC-UNIVALI. Essa formação teve variações ao longo dos anos, principalmente, na maneira de efetuá-la, mas se mantém até os dias atuais, o que consolidou o programa. O importante é registrar que existem, com maior ou menor variância, dois aspectos fundamentais. O primeiro, a temática central, que se desenvolve em todos campi e, atualmente, é desenvolvida por um grupo de formadores, capacitado pela própria Vice-Reitoria de Graduação e sua equipe. E, o segundo, o respeito à valorização da especificidade da área de conhecimento que cada Centro possui dentro de uma Universidade. A ideia que vigora, neste Programa, é dar organicidade e apresentar uma fala com uma linguagem unificada e articulada, principalmente quando o eixo temático central é novo. Este procedimento é efetuado em razão dos diferentes campi da UNIVALI e, além disso, para nortear ações e procedimentos comuns e integradores, em torno de uma política institucional, definida a partir do Plano de Desenvolvimento Institucional, onde há metas anuais a serem cumpridas (UNIVALI, 2001; UNIVALI, 2002; FERRI, 2009).

É interessante ver a mobilização dos formadores neste Programa, atuando com esmero, aprofundamento, exercício didático-pedagógico, compromisso e competência docente profissional. A contribuição desses profissionais é inegável e, na instituição, essa doação espontânea, generosa e socializadora é merecedora de elogios e reconhecimentos. $\mathrm{O}$ formador não recebe nenhum honorário pelo seu trabalho no Programa. Talvez, a origem institucional proveniente da manifestação e vontade popular dessas instituições, bem como as características institucionais de trabalho em prol da comunidade sem fins lucrativos sejam a marca mais forte que se materializa em ações dos docentes que nela atuam. Este é um dos itens que sempre gerou admiração institucional, aliado ao orgulho que se tem desses docentes profissionais que engrandecem e enobrecem a UNIVALI.

Estudos e pesquisas já realizadas (LUZ, 2007; FERRI, 2009) referentes ao Programa, revelaram resultados sobre as contribuições significativas, os seus avanços, bem como tensões, conflitos e dificuldades ocorridas nele. Mas, de forma geral, pode-se resumir que a UNIVALI ganhou muita cultura e identidade institucional, não só com esse Programa, que possui um caráter organizativo de diferentes ações do processo de ensino-aprendizagem para o diálogo criativo e de mudanças.

É por meio da formação continuada que se torna possível valer-se da própria experiência do magistério para refletir sobre a prática pedagógica vivenciada. É fundamental que os docentes manifestem abertura sobre a forma do quê e como se relaciona o que ensinam, dispondo-se a um contínuo dar e receber, assumindo responsabilidades conjuntas pela orientação do trabalho e sendo capaz de construir soluções para os problemas baseados em respeito às diferenças e particularidades individuais. 
Nesta perspectiva foi elaborado um texto, de quatro subitens, evidenciando o olhar das formadoras para a FC-UNIVALI.

\section{Significado de Ser Formadora}

Participar da FC-UNIVALI implica não só o aprofundamento e/ou domínio de conhecimentos, de saberes, de fazeres de determinada especialidade, mas também o desenvolvimento da sensibilidade do docente como pessoa e profissional em termos de atitudes e valores, tendo a reflexão como componente intrínseco ao processo de ensinar, de aprender, de formar-se e, consequentemente, de se desenvolver profissionalmente (BOLZAN e ISAIA, 2006). Esse processo de reflexão crítica terá avanços sobre as questões pedagógicas,

[...] à medida que buscarmos compreender as relações recíprocas existentes entre o
domínio do saber (conhecimento científico) e o domínio do saber fazer
(conhecimento prático). O processo de pensamento do professor e suas formas de
conceber e desenvolver o ensino explicita como este sistema de concepções
pessoais se desdobra, transformando-se em conhecimento pedagógico
compartilhado (BOLZAN e ISAIA, 2006, p. 492).

A troca e/ou socialização de conhecimentos específicos da área de atuação e do pedagógico, bem como a relação entre eles num movimento recorrente, dialético e muitas vezes, sedutor e encantador, contribuem efetivamente para a reflexão sobre a própria prática, formando e transformando a atuação individual e coletiva do corpo docente. $\mathrm{O}$ compartilhamento de saberes e fazeres fomenta a criatividade, o espírito investigativo e possibilita a compreensão que a docência profissional individual e coletiva é um processo em construção permanente.

Os professores que não apresentam formação na área didática se sentem provocados quando se vêm diante do desafio de auxiliar os seus alunos na construção e apropriação de conceitos científicos específicos que dominam, mas desconhecem os pressupostos epistemológicos de "como os alunos aprendem" ou quais metodologias estão envolvidas nos processos de ensino e aprendizagem, razão pelas quais em determinados momentos sentem-se desanimados, angustiados e incapacitados.

As participações nas oficinas da FC-UNIVALI provocam um sentimento de amparo no momento da percepção de que tais angústias não são isoladas e podem ser compartilhadas, havendo de outro lado, um grupo de especialistas que acolhe, oferecendo este auxílio. A provocação e o envolvimento com a prática docente revelam a complexidade do processo de ensino e aprendizagem e evidencia o inacabamento da construção do conhecimento, acompanhando o movimento e evolução constante do seu entorno, seja tecnológico, social ou cultural. Esta complexidade e a percepção de inacabamento obrigam os professores a se tornarem participantes ativos nesse movimento, minimizando o distanciamento entre a prática docente, os conhecimentos didático-pedagógicos e os conhecimentos específicos da área de atuação numa perspectiva integradora. 
Este programa trouxe muitos significados como formadora, mas a principal aprendida foi a necessidade da apresentação de habilidades e competências exemplificadoras, pois uma interlocução profícua com seus pares exige evidências de atitudes, principalmente, as de respeito, humildade e diálogo, já corroboradas também por diferentes autores (BATISTA e BATISTA, 2002; BORDAS, 2006; BAZZO, 2006; LUZ, 2007). Destacam-se como as mais significativas: trabalho em equipe; flexibilidade; espírito investigativo e inovador; generosidade e amorosidade intelectual; atualização tecnológica; autocrítica; tolerância; gerenciamento do inesperado; desenvolvimento do espírito colaborativo; enfrentamento de resistências e de conflitos; criação de espaços e modalidades de discussão; abertura ao debate e ao diferente; a inter-relação teoria-prática; investigação como forma de reflexão interdisciplinar e transdisciplinar do ensino e aprendizagem; desenvolvimento da autonomia individual/coletiva e da criatividade.

Ressalta-se, por fim, que atuar como formadora de docentes não sendo especializada na área pedagógica, exige um novo repensar dos seus próprios processos pedagógicos e a elaboração do próprio conhecimento sobre essa prática. Permite provocar, buscar e quem sabe criar, novos instrumentos, estratégias e ferramentas de processos pedagógicos a partir da socialização dos sucessos e fracassos pedagógicos vivenciados e experimentados. As trocas e socializações dessas experiências ampliam o campo da sala de aula, das estratégias de ensino, dos processos e instrumentos avaliativos, quebram paradigmas metodológicos de educação, objetivando a melhoria na construção do conhecimento do aluno e, consequentemente, da qualidade do ensino superior (OLIVER e BARRETO, 2010).

Nessa perspectiva o olhar das formadoras para a FC-UNIVALI possui muitos aspectos positivos, o que valoriza os aspectos pessoais e profissionais dos docentes do ensino superior.

\section{Aspectos positivos}

Como aspectos positivos, a FC-UNIVALI tem formado redes de colaboração e de negociação a ela entrelaçada, condição esta, inevitável no mundo da educação. Por outro lado, convoca os professores, para que juntos possam superar obstáculos e fazer frente à vulnerabilidades e frustrações, através da capacidade de reflexão e da atuação como professor pesquisador.

Tal rede de colaboração impregna na formadora o sentimento de pertencimento e corresponsabilidade por esse processo, uma vez que o aprofundamento dos estudos sobre como nos constituímos como sujeitos da docência, passa a ser responsabilidade de cada um e do coletivo, ao mesmo tempo. Dialogar com os pares de diferentes áreas do conhecimento proporciona o enriquecimento coletivo e é benéfico para todos.

Concretizar uma construção coletiva de conhecimento de diferentes saberes vai ao encontro do pensamento freireano: "Quem forma se forma e re-forma ao formar e quem é formado forma-se e forma ao ser formado" (FREIRE, 2010, p. 23). Ao colocar-se como

\begin{tabular}{l|l|l|l|l|l|l} 
(C) Rev. Inter. Educ. Sup. & Campinas, SP & v.2 & n.2 & p.366-381 & maio/ago. 2016 & ISSN 2446-9424
\end{tabular}


formadora é necessário colocar-se na condição de sujeito consciente do seu inacabamento, do vir a ser, daquilo que ainda não é, e por isso mesmo, aberto à procura, no processo de ensino e aprendizagem. Aprender "é construir, reconstruir, constatar para mudar, o que não se faz sem abertura ao risco e à aventura do espírito" (FREIRE, 2010, p.69).

Ainda como aspectos positivos da FC-UNIVALI, destacam-se, a aprendizagem com os colegas profissionais docentes, em nível de organização, condução, dinâmica, profundidade, versatilidade e tipo de aula ministrada, evidenciando as competências, habilidades e atitudes exemplificadoras.

Durante as oficinas da FC-UNIVALI, a apresentação da fundamentação teórica, a seleção da estratégia didática e as exemplificações diferenciadas que possibilitam a aplicação em sua prática docente são elementos que favorecem a construção do conhecimento e o diálogo interdisciplinar entre os pares de uma mesma instituição, promovendo o enriquecendo mútuo para as formadoras e os docentes participantes.

Por meio das narrativas dos docentes infere-se que o conhecimento compartilhado potencializa a reestruturação individual e coletiva de conhecimentos específicos da área de atuação e os saberes didático-pedagógicos. Ao partilhar inquietações, angústias, incertezas e apostas, o processo formativo pode ser fortalecido por meio da análise da própria atividade docente e da reconstrução de ideias provocadas por diferentes discursos mediadores que pressupõe a inter-relação teoria e prática.

E assim, a formadora ingressa no campo de que formar é preparar para a mudança nas dimensões básicas do ser humano: conhecimentos, sentimentos e atitudes; habilidades e vontade ou empenho na realização de tarefas tendo em vista a integração de processos de formar (desenvolvimento profissional), inovar (melhoria colaborativa) e investigar (conhecer para melhorar). Inovar para formar, formar para inovar (TORRE e BARRIOS, 2002).

Mas, a par das considerações positivas que as formadoras observaram na FCUNIVALI não se pode deixar de pontuar seus conflitos, tensões e dificuldades.

\section{Conflitos, tensões e dificuldades}

Nesse movimento, os conflitos se fazem presentes, pois são muitos, ainda, os “[...] professores que exercem duas atividades: a de profissional de determinada área e a de docente, com predominância da primeira. Por essa razão tendem a conferir menos atenção às questões de natureza didática [...]" (GIL, 2010, p.5). Aparecem situações delicadas que exigem paciência e persistência na atuação como formadora. Lidar com os desejos, carências e fragilidades divergentes, no momento da oficina, é exercitar a escuta respeitosa. Ser formadora de seus pares exige coragem. Ser formadora exige o assumir da função social de "retomar o passado, refazer os vínculos com o presente, reorganizar o futuro" (CODO e MENEZES, 1999, p. 44). 
Ainda no campo dos conflitos, as formadoras percebem, consoante a Mantovani e Canan (2015), a presença de dois tipos de professores participantes das oficinas: a) formado por profissionais da área específica, conforme já apresentado e b) aqueles com larga experiência na área pedagógica. Para o primeiro grupo, evidencia-se a necessidade, pela formadora, de romper com o bloqueio e negação à abertura aos novos processos necessários para o processo de ensino e aprendizagem. Para estes professores, sensibilizá-los desta necessidade parece o maior desafio como formadora, o que está corroborado por outros autores (MANTOVANI e CANAN, 2015; ALTHAUS e GÓES, 2013). Em relação ao segundo grupo, as formadoras, que não são especialistas na área pedagógica, percebem os enfrentamentos de "estar em um local onde não deveria estar" e o desafio, real ou imaginário, da necessidade de evidenciar fundamentação em uma área sem domínio, mas apenas expondo "experimentos pedagógicos diferenciados" com resultados positivos na sua área ou especialidade.

No campo da tensão, salienta-se o processo de planejamento, que envolve a execução do plano de ação junto aos colegas, visando transcender os limites circunscritos do próprio campo de atuação, superando uma visão meramente técnica. Essa atividade requer a competência de reanalisar a prática docente, o papel da docência e sua função social, correlacionados com a missão, visão e valores institucionais já pontados anteriormente (PEREIRA, 2004).

Com relação às dificuldades, também precisam ser contornadas com discernimento: número de participantes; tipo de profissionais preponderantes, pois a inscrição é livre e ocorre conforme vontade e escolha do docente; existência de problematização e diversidade de exemplos para atingir as diferentes áreas de conhecimento; adequação do conteúdo planejado e o total de horas/aula destinada; dinâmica para incentivar, encantar e envolver os participantes; avaliação objetiva, clara e direta para assegurar o feedback à proposta construída.

Como último subitem, cabe considerar que existem aspectos indispensáveis que o formador deve considerar no ato de formação e que do olhar das formadoras são vitais.

Aspectos indispensáveis do olhar das formadoras no ato da formação

As discussões e experiências relatadas, neste artigo, por parte das formadoras com relação à prática com docentes do ensino superior revelam, pelo menos, dois aspectos: o conhecimento epistemológico da educação e o conhecimento didático-pedagógico.

O conhecimento epistemológico da educação é a base da práxis. A compreensão epistemológica, a respeito do ensino e da aprendizagem, poderá melhorar as mediações nos processos ensino-aprendizagem, tanto promovendo o desenvolvimento do pensamento crítico do professor e do aluno, quanto permitindo que se encontrem soluções diferentes para 
mesmas situações, com mais de uma alternativa para a resolução de problemas do cotidiano acadêmico e profissional.

Durante as reflexões nas situações da FC-UNIVALI, acentua-se o pensamento dos pares, quando se provoca ou os desafia para as concepções de mundo, sociedade, conhecimento, ser humano, educação, entre outros.

O segundo aspecto a ser considerado, como indispensável para as formadoras no ato da formação, é o conhecimento didático-pedagógico. Este aspecto permeia todos os meios educativos, pois, a preocupação com a formação e o desenvolvimento profissional de professores universitários e com a inovação didática cresce nos meios educativos, o que é atestado pelo aumento progressivo de congressos, reuniões, seminários e atividades relacionadas ao tema [...]. A preocupação com a qualidade dos resultados do ensino superior, sobretudo os de graduação, revela a importância da preocupação política, científica e pedagógica de seus docentes (PIMENTA e ANASTASIOU, 2010, p. 249).

O formador, no ato da formação dos seus pares, necessita fortalecer que a sala de aula além de ser um espaço físico, é um espaço social de trocas, negociações, pesquisas, ensinoaprendizagens e intercâmbios. Afirmam Sacristán e Pérez-Gomes (1998, p. 85) que "[...] a vida em sala de aula deve ser interpretada como uma rede viva de troca, criação, transformação e significados". É, neste sentido, que durante as formações realizadas ressaltase a importância de uma metodologia de ensino, para a aprendizagem, que responda às questões sobre o que é ser professor? O que é ensinar? Quem é o aluno que está na frente do docente? O que o aluno precisa aprender? O que o docente precisa para ensinar? Como se pode ajudar o aluno a aprender? Como verificar se o aluno aprendeu?

Estes questionamentos envolvem um processo de 'ensinagem', termo utilizado por Anastasiou, que passa a ser compreendida como um fórum em que se argumentam a respeito de concepções e de representações da realidade, negociando ações, que envolvam: alunos, professores e conhecimentos. Construir conhecimentos passa a ser uma rede viva de trocas e de transformação de significados.

\section{CONSIDERAÇÕES FINAIS}

Atuar como formadora é fazer da FC-UNIVALI um espaço e tempo de renovação, inovação e de protagonismo docente. É priorizar no cotidiano docente a transformação e a inquietude permanente do processo de ensino-aprendizagem. Implica em comprometer-se com o outro, com a transformação social e com aprendizagens significativas promotoras do desenvolvimento humano e social. É ter presente o exercício paciente do conhecimento epistemológico e do conhecimento didático-pedagógico, equilibrados, como exigências de uma prática docente renovada em sala de aula. É revitalizar o colega docente, mas também, revitalizar-se com ideias criativas e processos inovadores que energizam o cotidiano com 
algo diferente. É fazer do dia-a-dia um contínuo processo de reflexão-ação-reflexão e agir como professor pesquisador permanente de sua própria prática docente. É dar vida, dinâmica e inventividade no conhecer e no saber fazer do processo de ensino-aprendizagem. Enfim, ser formadora é exercitar e transitar no campo das atitudes, habilidades e competências da docência, do ser professor reflexivo e pesquisador, dialogando e superando os desafios, as complexidades e enfrentamentos pedagógicos, em prol do desenvolvimento humano, social e da qualidade do ensino superior estabelecido numa política de ensino institucional.

\section{REFERÊNCIAS}

ALTHAUS, Maiza Taques Margraf; GÓES, GracieteTozetto. Docência Universitária: Relato de Experiência com Professores Participantes de um Programa Institucional de Formação Pedagógica. In: CONGRESSO NACIONAL DE EDUCAÇÃO - EDUCERE, 11., Curitiba, 2013. Anais do.... Curitiba: PUCPR, 2013.

BALZAN, Newton Cesar. Do estudante ao professor universitário: caminhos para a didática do ensino superior. Revista de Educação, Campinas, v. 1, n.3, p.7-24, 1997.

BATISTA, Sylvia Helena Souza da Silva; BATISTA, Nildo Alves. A formação do professor universitário: desafios e possibilidades. In: SEVERINO, Antônio Joaquim; FAZENDA, Ivani Catarina Arantes (Org). Formação docente: rupturas e possibilidades. Campinas: Papirus, 2002.

BAZZO, VV. L. Uma experiência de formação para professores do ensino superior.

Disponível em: <http://www2.uerj.br/ anped 11>. Acesso em: 30 mar. 2006.

BOLZAN, Doris Pires Vargas, ISAIA, Silvia Maria de Aguiar. Formação de professores: a construção da docência e da atividade pedagógica na Educação Superior. Revista Diálogo. Curitiba, v.13, p.38, p.49-68, jan./abr. 2013.

BOLZAN, Doris Pires Vargas.; ISAIA, Silvia Maria De Aguiar ISAIA. Aprendizagem docente na educação superior: construções e tessituras da professoralidade. Educação, Porto Alegre, v.29, n.3 (60), p.489-501, set./dez., 2006. Disponível em: < http://revistaseletronicas.pucrs.br/ojs/index.php/faced/article/viewFile/489/358 >. Acesso em: 19 ago. 2016.

BORDAS, Mérion Campos. Formação de professores do ensino superior: aprendizagens da experiência. Disponível em: <http://www2.uerj.br/ anped 11〉. Acesso em: 30 mar. 2006.

CODO, Wanderley e MENEZES, Iône Vasques. Educar, educador. In: CODO, Wanderley (Org.). Educação: carinho e trabalho. Petrópolis: Vozes, 1999.

FERRI, Cássia. Formação continuada de professores universitários: a experiência da Universidade do Vale do Itajaí. In: ISAIA, Silvia Maria de Aguiar: BOLZAN, Doris Pires de Vargas (Org.). Pedagogia universitária e desenvolvimento profissional docente. Porto Alegre: EDIPUCRS, 2009. 
FREIRE, Paulo. Pedagogia da autonomia: saberes necessários à prática educativa. 41 ed. Rio de Janeiro: Paz e terra, 2010.

GIL, Antonio Carlos. Didática do ensino superior. São Paulo: Atlas, 2010.

LUZ, Sueli Petry da Formação continuada para docentes da educação superior: um estudo de caso. 2007. 227f. Tese (Doutorado em Educação). Faculdade de Educação, Universidade Estadual de Campinas, Campinas.

MANTOVANI, Isabel Cristina de Almeida, CANAN, Silvia Regina. Política de Formação para Professores do Ensino Superior e Qualidade de Ensino: um estudo sobre o Programa Pedagogia Universitária como possibilidade de qualificação docente na perspectiva pedagógico-didática. Rev. Inter. Educ. Sup. Campinas. v.1 n.2 p.136-148 out./dez. 2015.

NÓVOA, António. A formação de professores e profissão docente. In: NÓVOA, António (Coord). Os professores e a sua formação. Lisboa: Dom Quixote, 1995. 157 p., p. 15-33.

OLIVER, Ana Cristina; BARRETO, Maribel Oliveira. Assessoria Pedagógica a docentes Universitários: relato de experiência. Est. Aval. Educ. São Paulo, v.21, n.46, p.375-386, maio/agosto, 2010.

PACHANE, Graziela Giusti. A importância da formação pedagógica para o professor universitário: a experiência da UNICAMP. Campinas, 2003 b. In: PEREIRA, Elisabete Monteiro de Aguiar Pereira (Coord.) Ciclo de Palestras: Educação Superior em vários enfoques. Campinas: Grupo de Estudos e Pesquisas em Educação Superior - GEPES, 2003b. 1 fita cassete (120 minutos). Transcrita por Sueli Petry da Luz.

PACHANE, Graziela Giusti G. A importância da formação pedagógica para o professor universitário: a experiência da UNICAMP. 2003a. 268 f. Tese (Doutorado em Educação) Faculdade de Educação, Universidade Estadual de Campinas, Campinas.

PEREIRA, Yára Christina Cesário. Formação e docência: a construção de um conhecimento integrado no curso de pedagogia - mobilizando saberes e enfrentando incertezas no ensino de Ciências Naturais. 2004. 264. Tese. (Programa de Pós-Graduação em Educação. Curso de Doutorado em Educação. Universidade Federal de Santa Catarina, Florianópolis, 2004.

PIMENTA, Selma Garrido; ANASTASIOU, Léa das Graças Camargo. Docência no ensino superior. 4.ed. São Paulo: Cortez, 2010.

SACRISTÁN, J. Gimeno; PEREZ-GOMES, Angel I. Compreender e transformar o ensino. Porto Alegre: ArtMed, 1998.

TORRE, S. DE La; BARRIOS, Oscar. Curso de Formação para Educadores. São Paulo: Madras, 2002.

UNIVERSIDADE DO VALE DO ITAJAÍ - UNIVALI. Pró-Reitoria de Ensino. Formação continuada para docentes do ensino superior: curso de atualização pedagógica presencial. Orgs. Sueli Petry da Luz e Amândia Maria de Borba. Itajaí: UNIVALI, 2001. 
UNIVERSIDADE DO VALE DO ITAJAÍ - UNIVALI. Pró-Reitoria de Ensino. Formação continuada para docentes do ensino superior: apontamentos para novas alternativas pedagógicas. Coords. Amândia Maria de Borba; Sueli Petry da Luz. Itajaí: UNIVALI, 2002.

UNIVERSIDADE DO VALE DO ITAJAÍ - UNIVALI. Plano de Desenvolvimento Institucional - PDI 2012-2016. Itajaí: UNIVALI, 2012.

UNIVERSIDADE DO VALE DO ITAJAÍ - UNIVALI. Estatuto da Fundação UNIVALI: aprovado pela Resolução n. 006/ CAS/ 2014, de 25 de março de 2014. Itajaí, 2014a.

UNIVERSIDADE DO VALE DO ITAJAÍ - UNIVALI. Estatuto da UNIVALI: aprovado pela Resolução No 97/ CONSUN/ 2014, de 29 de outubro de 2014 e homologado pela Resolução n. 123/ CONSUN/2014, de 16 de dezembro de 2014 - oitavo alteração. Itajaí: Reitoria da UNIVALI, 2014b.

UNIVERSIDADE DO VALE DO ITAJAÍ - UNIVALI.2016a. Disponível em: <http://www.univali.br.> Acesso em: ago.2016.

UNIVERSIDADE DO VALE DO ITAJAÍ - UNIVALI. Formação Continuada. Itajaí: UNIVALI, $2016 \mathrm{~b}$.

VEIGA, Ilma Passos Alencastro, RESENDE, Lúcia Maria Gonçalves de, FONSECA, Marília. Aula universitária e inovação. In: VEIGA, Ilma Passos Alencastro. CASTANHO, Maria Eugênia L. M. (Org.). Pedagogia universitária: a aula em foco. Campinas, Papirus, 2000 . 